\title{
P4HB promotes HCC tumorigenesis through downregulation of GRP78 and subsequent upregulation of epithelial-to- mesenchymal transition
}

\author{
Wei Xia ${ }^{1, *}$, Juhua Zhuang ${ }^{1, *}$, Guoyu Wang ${ }^{1}$, Jing $\mathrm{Ni}^{1}$, Jiening Wang ${ }^{2}$, Ying $\mathrm{Ye}^{1}$ \\ ${ }^{1}$ Department of Nuclear Medicine, Seventh People's Hospital of Shanghai University of TCM, Shanghai, China \\ ${ }^{2}$ Department of Integrated TCM \& western medcine, President's Office of Seventh People's Hospital of Shanghai University \\ of TCM, Shanghai, China \\ *These authors have contributed equally to this work and should be considered as co-first authors \\ Correspondence to: Jiening Wang, email: doctorwjn@126.com \\ Ying Ye, email: doctoryeying@126.com
}

Keywords: P4HB, GRP78, hepatocellular carcinoma, tumorigenesis, epithelial-to-mesenchymal transition

Received: July 25, 2016

Accepted: December 01, 2016

Published: December 28, 2016

\section{ABSTRACT}

P4HB and GRP78 are molecular chaperones involved in cellular response to ER stress. They have been linked to cancer progression; however, their roles in hepatocellular carcinoma (HCC) are largely unclear. In this study, we found that P4HB is overexpressed in human HCC tissues and cell lines. Higher tumoral P4HB levels are correlated with more advanced disease and poorer survival. GRP78 expression is inversely correlated with P4HB in human HCC tissues, and downregulated by P4HB in HCC cell lines. P4HB overexpression promotes HCC cell growth, migration, invasion and epithelial-to-mesenchymal transition (EMT) in vitro. GRP78 overexpression not only inhibits HCC cell growth, migration, invasion and EMT, but also antagonizes the oncogenic effects of P4HB overexpression. Furthermore, P4HB silencing inhibits HCC tumorigenesis in vivo. Taken together, our results provided evidence that P4HB promotes HCC progression through downregulation of GRP78 and subsequent upregulation of EMT.

\section{INTRODUCTION}

Tumor cells are often exposed to hypoxia and nutrient deprivation. These unfavorable conditions result in accumulation of unfolded proteins in the ER, causing ER stress. This triggers a defensive process known as the "unfolded protein response" or UPR. UPR allows tumor cells to adapt to ER stress and thereby safeguards their survival [1]. Compelling evidence shows that UPR is activated in many cancers, and plays a critical role in cancer progression [2-4].

The 78-kilodalton glucose regulated protein (GRP78/BiP) is a multifunctional protein belonging to the heat shock protein 70 family. GRP78 is the most abundant ER chaperone and functions as a gatekeeper of the mammalian UPR [5]. GRP78 promotes tumor growth, survival and metastasis; and is generally considered to play an oncogenic role in cancer [6]. However, a number of studies suggest that GRP78 can also function as a tumor suppressor in certain cancer types. For example, colon cancer cells with surface expression of GRP78 exhibit reduced proliferation, tumor growth, and metastasis, while GRP78 knockdown restores tumorigenicity of these cells [7]. Additionally, GRP78 knockdown increases the migratory ability of colon cancer and hepatocellular carcinoma (HCC) cells through upregulation of epithelialto-mesenchymal transition (EMT) $[8,9]$. These results suggest that the role of GRP78 in tumorigenesis can be context-dependent.

Prolyl 4-hydroxylase, beta polypeptide (P4HB), the beta subunit of prolyl 4-hydroxylase, can act as a ER chaperone to inhibit aggregation of misfolded proteins [10]. Recent studies have shown that P4HB is upregulated in many cancer cell types, and its expression correlates with cancer progression and clinical outcome [11]. For example, higher P4HB levels are associated with more advanced disease and drug resistance in malignant glioma, and P4HB inhibition increases the chemosensitivity of drug-resistant glioma cells $[12,13]$. $\mathrm{P} 4 \mathrm{HB}$ is overexpressed in non-small cell lung cancer (NSCLC), and decreased P4HB expression following drug treatment predicts better clinical outcome [14]. 
These findings demonstrate the potential oncogenic properties of $\mathrm{P} 4 \mathrm{HB}$ in cancer. However, the role of $\mathrm{P} 4 \mathrm{HB}$ in $\mathrm{HCC}$ remains unclear.

In this study, we determined $\mathrm{P} 4 \mathrm{HB}$ levels in tumor and adjacent normal tissues of HCC patients. We also assessed the correlations between tumoral $\mathrm{P} 4 \mathrm{HB}$ and disease stage, metastasis and patient survival. Moreover, the role of $\mathrm{P} 4 \mathrm{HB}$ in $\mathrm{HCC}$ tumorigenesis in vitro and in vivo, as well as the underlying mechanisms involving GRP78 were investigated. Our data supported P4HB as a potential diagnostic/prognostic marker and therapeutic target for HCC.

\section{RESULTS}

\section{P4HB is upregulated in HCC and is inversely correlated with HCC patient survival}

To find out whether P4HB is dyregulated in HCC, we determined $\mathrm{P} 4 \mathrm{HB}$ mRNA and protein levels in tumor and adjacent normal liver tissues of HCC patients by qRT-PCR and western blotting, respectively. Our data revealed higher $\mathrm{P} 4 \mathrm{HB} \mathrm{mRNA}$ and protein levels in $\mathrm{HCC}$ tissues compared with adjacent normal tissues (Figure 1B, 1C). Moreover, Kaplan-Meier analysis revealed a
A
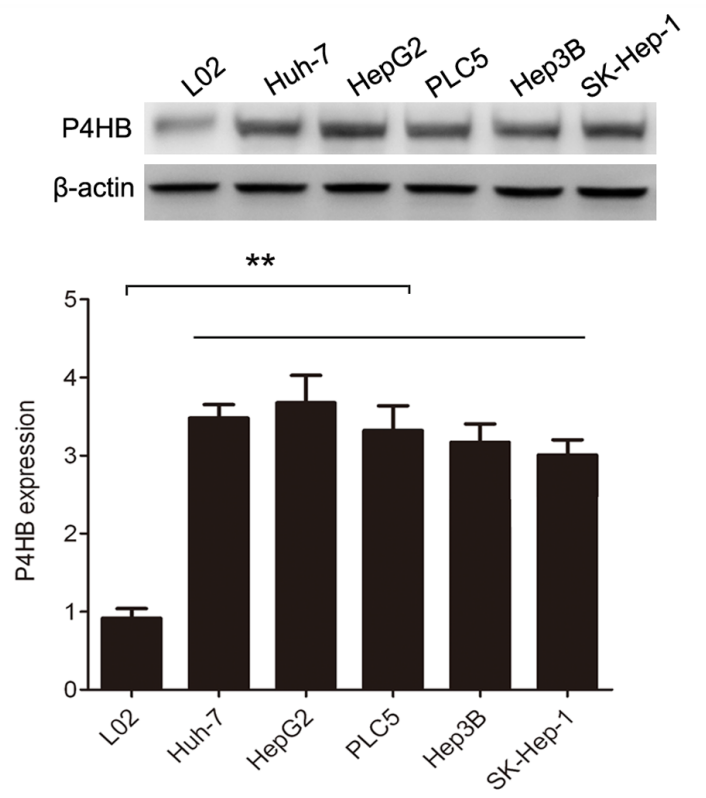

D



B

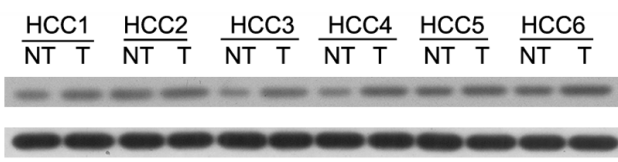

$\beta$-actin $\frac{\mathrm{HCC} 7}{\mathrm{NTT}} \frac{\mathrm{HCC} 8}{\mathrm{NT} T} \frac{\mathrm{HCC9}}{\mathrm{NT} T} \frac{\mathrm{HCC} 10}{\mathrm{NT} T} \frac{\mathrm{HCC} 11}{\mathrm{NT} \mathrm{T}} \frac{\mathrm{HCC} 12}{\mathrm{NTT}}$

$\mathrm{P} 4 \mathrm{HB}$

$\beta$-actin

C



Figure 1: $\mathrm{P} 4 \mathrm{HB}$ is upregulated in human $\mathrm{HCC}$ and is inversely correlated with $\mathrm{HCC}$ patient survival. A. $\mathrm{P} 4 \mathrm{HB}$ protein expression in HCC cell lines (Huh-7, HepG2, PLC5, Hep3B, and SK-Hep-1) and the normal liver cell line L02 by western blotting. $\beta$-actin was used as a loading control. $\mathrm{n}=3,{ }^{* *} P<0.01$. B. P4HB protein expression in paired human HCC and adjacent normal liver tissues by western blotting (12 pairs are shown). $\beta$-actin was used as a loading control. T, tumor tissue; NT, adjacent normal liver tissue. C. P4HB mRNA expression in paired human HCC and adjacent normal liver tissues by qRT-PCR. $\mathrm{n}=42, * * P<0.01$. D. Kaplan-Meier analysis of HCC patient survival rate in relation to tumoral P4HB protein expression. P4HB above median, tumoral P4HB $>2.5$-fold of adjacent normal tissue; $\mathrm{P} 4 \mathrm{HB}$ below median, tumoral $\mathrm{P} 4 \mathrm{HB}<2.5$-fold of adjacent normal tissue. Patient survival was inversely correlated with tumoral P4HB $(P=0.0003)$. 
Table 1: Correlative Analysis of P4HB protein Levels With Clinicopathological Features

\begin{tabular}{|c|c|c|c|c|}
\hline \multirow{2}{*}{$\begin{array}{l}\text { Clinicopatholigic } \\
\text { Parameters }\end{array}$} & \multirow{2}{*}{$\begin{array}{c}\text { No. of } \\
\text { Specimens }\end{array}$} & \multicolumn{2}{|c|}{$\begin{array}{l}\text { P4HB Expression } \\
\text { (Tumor/Nontumoral) }\end{array}$} & \multirow[t]{2}{*}{ P Value } \\
\hline & & Low & High & \\
\hline Sex & & & & NS \\
\hline Female & 35 & 16 & 19 & \\
\hline Male & 7 & 4 & 3 & \\
\hline Age & 42 & $51.6 \pm 10.5$ & $53.9 \pm 9.8$ & NS \\
\hline Grade & & & & NS \\
\hline 1 & 10 & 9 & 1 & \\
\hline 2 & 17 & 7 & 10 & \\
\hline 3 & 15 & 4 & 11 & \\
\hline Stage & & & & 0.009 \\
\hline 1 & 16 & 12 & 4 & \\
\hline 2 or 3 & 26 & 8 & 18 & \\
\hline Multiple tumor & & & & 0.02 \\
\hline No & 26 & 14 & 12 & \\
\hline Yes & 16 & 6 & 10 & \\
\hline $\begin{array}{l}\text { Vascular invasion } \\
\text { (macro) }\end{array}$ & & & & 0.006 \\
\hline No & 18 & 12 & 6 & \\
\hline Yes & 24 & 8 & 16 & \\
\hline $\begin{array}{l}\text { Vascular invasion } \\
\text { (micro) }\end{array}$ & & & & 0.001 \\
\hline No & 16 & 13 & 3 & \\
\hline Yes & 26 & 7 & 19 & \\
\hline $\mathrm{HBV}$ & & & & NS \\
\hline No & 5 & 3 & 2 & \\
\hline Yes & 37 & 17 & 20 & \\
\hline Cirrhosis & & & & NS \\
\hline No & 22 & 12 & 10 & \\
\hline Yes & 20 & 8 & 12 & \\
\hline
\end{tabular}

High tumoral P4HB expression was regarded at $>2.5$-fold up-regulation, relative to the adjacent nontumoral liver. Abbreviation: NS, no significant difference.

significant inverse correlation between HCC patient survival rate and tumoral $\mathrm{P} 4 \mathrm{HB}$ protein level (Figure $1 \mathrm{D}, P=0.0003)$. These data suggested that P4HB may serve as a diagnostic/prognostic marker for HCC. In addition, the HCC cell lines Huh-7, HepG2, PLC5, Hep3B, and SK-Hep-1 showed significantly higher $\mathrm{P} 4 \mathrm{HB}$ protein expression than the normal liver cell line L02 (Figure 1A).

\section{Higher P4HB levels are correlated with more advanced HCC and metastasis}

We subsequently analyzed the correlation between clinicopathological parameters of HCC patients and tumoral $\mathrm{P} 4 \mathrm{HB}$ protein levels. We found that P4HB levels were significantly correlated with the grade and stage of the disease, number of tumors, and vascular invasion (Table 1). These findings further supported the prognostic value of $\mathrm{P} 4 \mathrm{HB}$ in HCC. However, P4HB levels were not affected by patient gender or age.

\section{P4HB promotes HCC cell growth, migration, and invasion}

To find out whether P4HB promotes HCC tumorigenesis, we used HepG2 and Huh-7 cells transfected with $\mathrm{P} 4 \mathrm{HB}$ or $\mathrm{P} 4 \mathrm{HB}$ siRNA. Compared with controls, transfection with $\mathrm{P} 4 \mathrm{HB}$ and $\mathrm{P} 4 \mathrm{HB}$ siRNA led to enhanced and suppressed $\mathrm{P} 4 \mathrm{HB}$ expression, respectively (Figure 2A). Our data showed that $\mathrm{P} 4 \mathrm{HB}$ overexpression significantly enhanced HepG2 and Huh-7 cell growth, migration, and invasion while $\mathrm{P} 4 \mathrm{HB}$ silencing had the 
opposite effects (Figure 2B-2D). These results suggested that $\mathrm{P} 4 \mathrm{HB}$ plays an oncogenic role in $\mathrm{HCC}$.

\section{P4HB induces EMT of HCC cells}

Epithelial-mesenchymal transition (EMT) plays a key role in tumor progression, invasion, and metastasis [15]. In this study, we examined the function of P4HB in EMT of HCC cells by measuring the epithelial marker E-cadherin and the mesenchymal markers $\mathrm{N}$-cadherin and vimentin. $\mathrm{P} 4 \mathrm{HB}$ overexpression in HepG2 and Huh-7 cells led to significantly reduced E-cadherin expression along with increased $\mathrm{N}$-cadherin and vimentin expression; and P4HB silencing showed the opposite effects (Figure 3A). Immunofluorescence staining of E-cadherin and vimentin showed similar results (Figure 3B, 3C). Together, these data indicated that $\mathrm{P} 4 \mathrm{HB}$ induces EMT of HCC cells.

\section{P4HB downregulates GRP78 in HCC}

GRP78 has been reported to inhibit EMT of HCC cells [9]. To find out whether GRP78 is involved in EMT of $\mathrm{HCC}$ cells induced by $\mathrm{P} 4 \mathrm{HB}$, we examined the possible regulatory relationship between $\mathrm{P} 4 \mathrm{HB}$ and GRP78. P4HB overexpression significantly reduced while P4HB silencing significantly increased GRP78 mRNA and protein expression in HepG2 and Huh-7 cells (Figure 4A, 4B). These data suggested that $\mathrm{P} 4 \mathrm{HB}$ downregulates GRP78 in human HCC. Indeed, GRP78 mRNA levels in human HCC tissues were found to be inversely correlated with P4HB mRNA levels (Figure 4C).

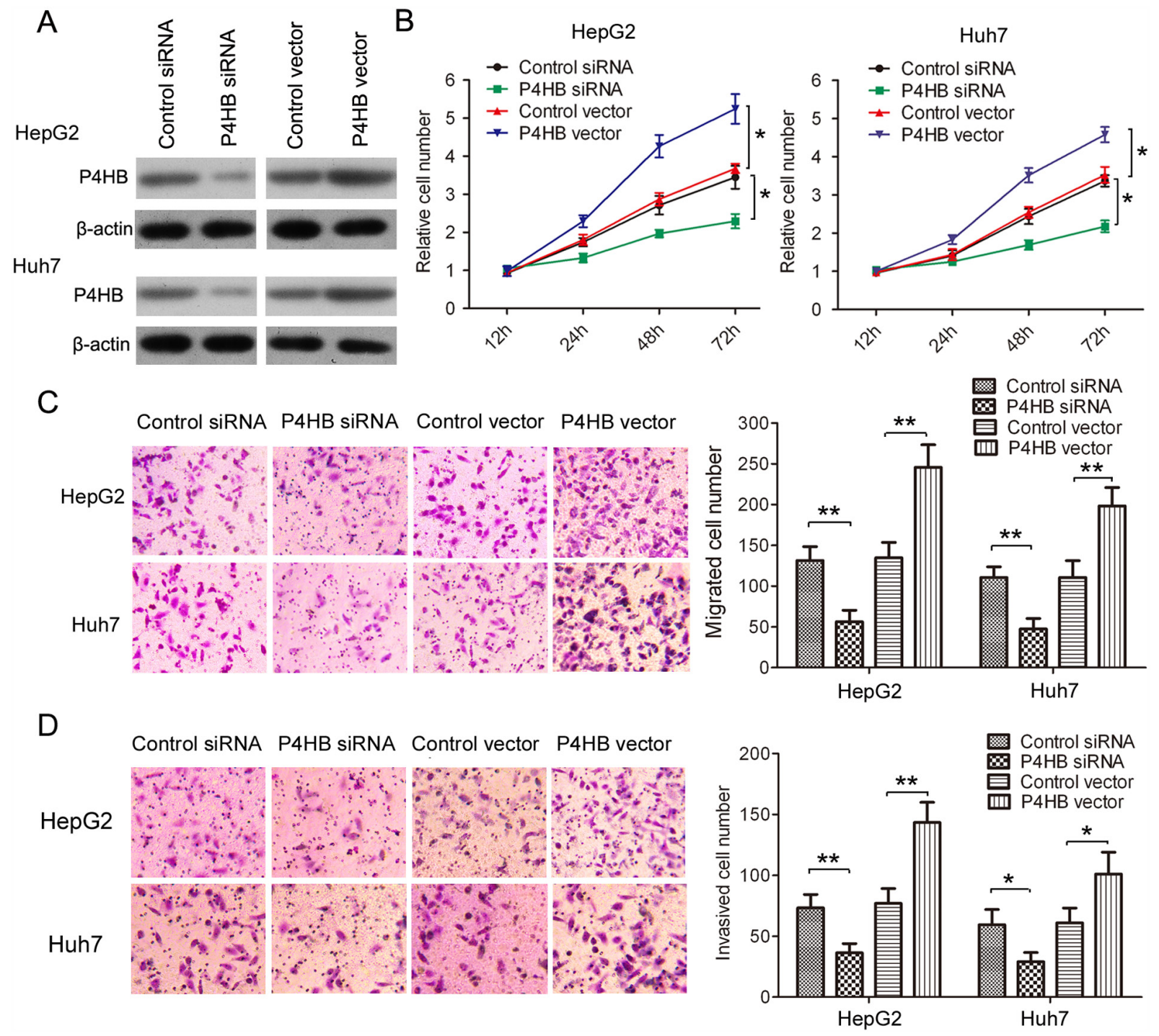

Figure 2: P4HB promotes HCC cell growth, migration, and invasion. HepG2 and Huh-7cells were transfected with P4HB siRNA, control siRNA, P4HB, or vector alone for $24 \mathrm{~h}$. A. P4HB protein expression determined by western blotting. $\beta$-actin was used as a loading control. B. Cell proliferation determined by the MTT assay. C and D. Cell migration (C) and invasion (D) determined by Transwell assays using un-coated and Matrigel-coated membranes, respectively. $\mathrm{n}=3,{ }^{*} P<0.05,{ }^{*} * P<0.01$. 

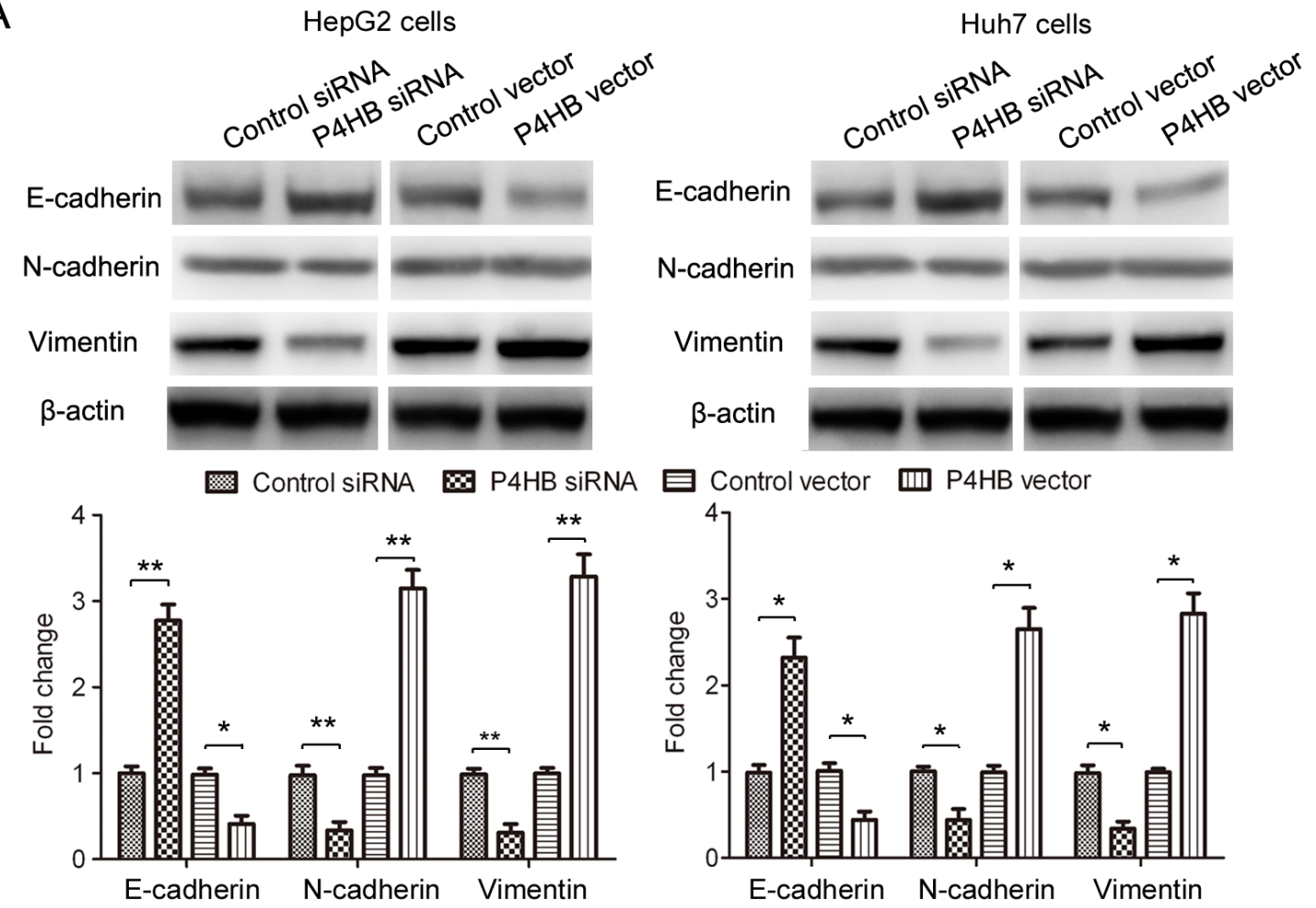

B

Control siRNA

P4HB siRNA
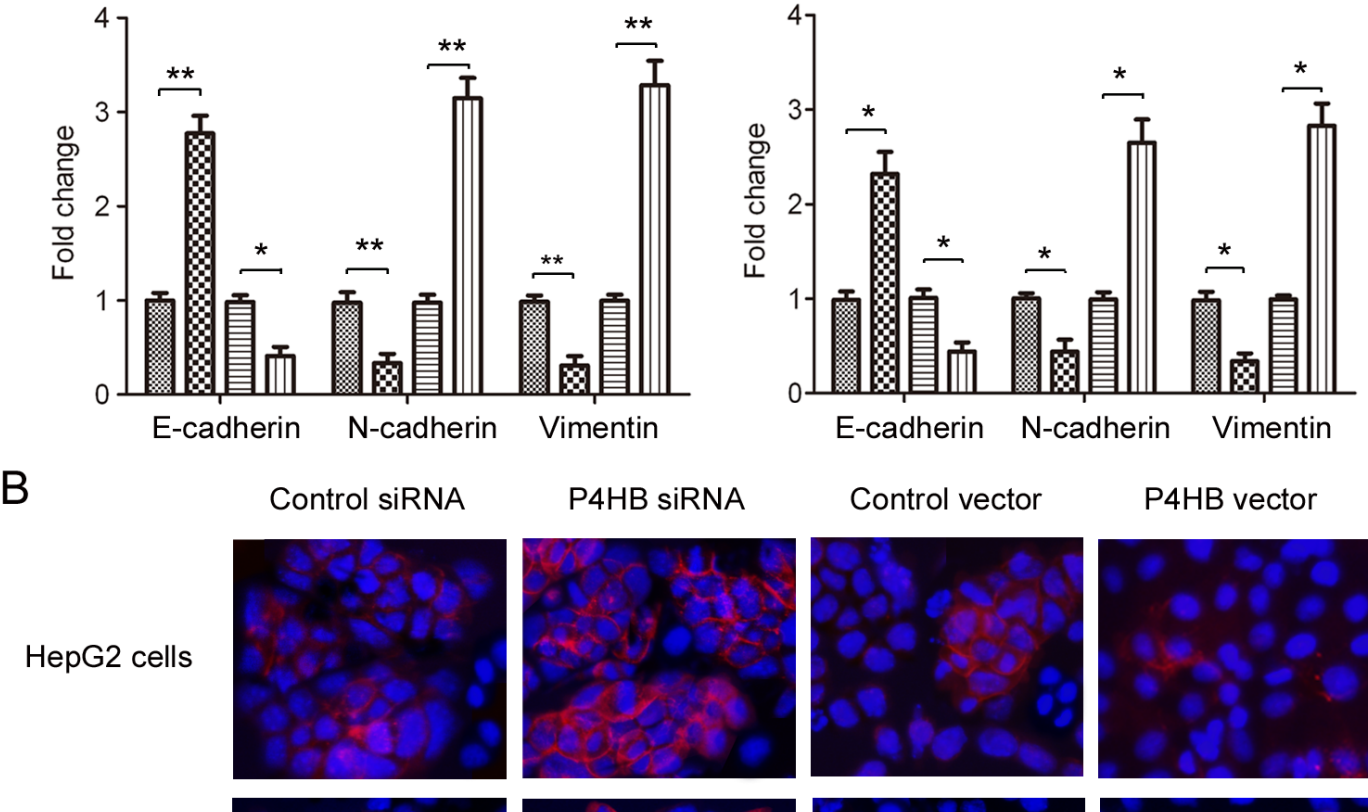

Control vector

P4HB vector

Huh7 cells
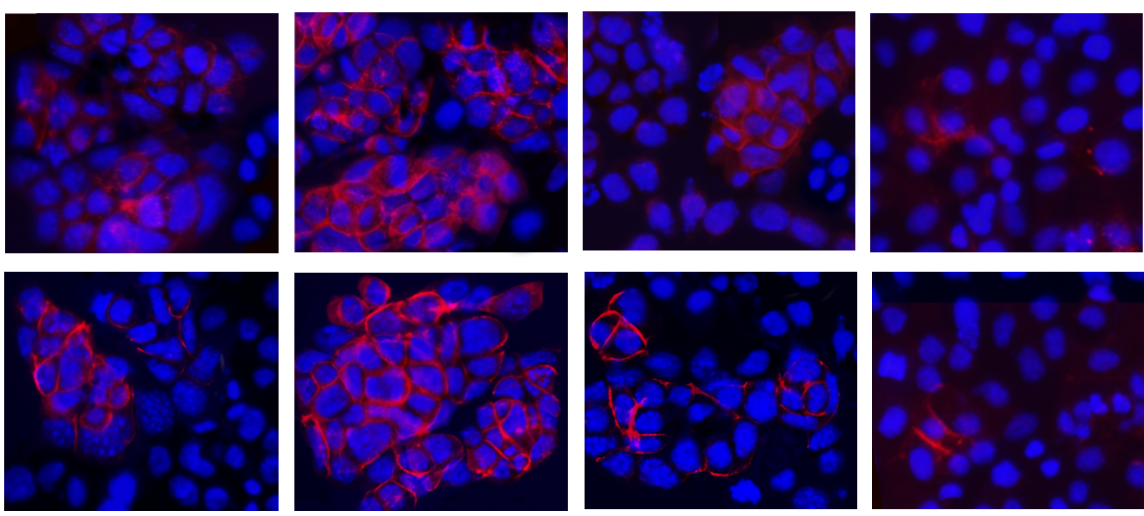

C
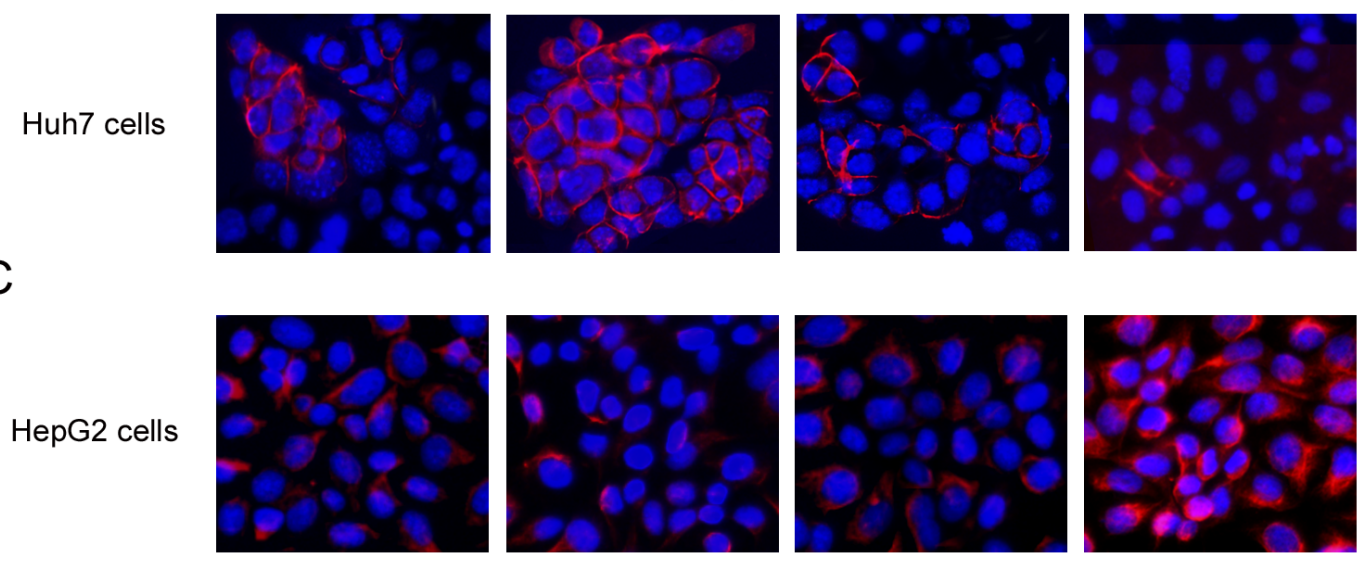

Huh7 cells
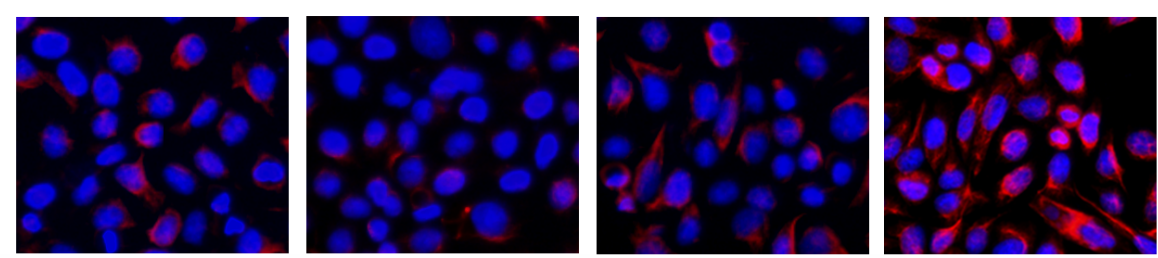

Figure 3: P4HB induces EMT of HCC cells. HepG2 and Huh-7 cells were transfected with P4HB siRNA, control siRNA, P4HB, or vector alone for $24 \mathrm{~h}$. A. Protein expression of the epithelial marker E-cadherin and the mesenchymal markers $\mathrm{N}$-cadherin and vimentin by western blotting. $\beta$-actin was used as a loading control. $\mathrm{n}=3, * P<0.05, * * P<0.01$. B and $\mathbf{C}$. Immunofluorescence analysis for E-cadherin (B) and vimentin (C) expression. 


\section{P4HB promotes HCC cell EMT, migration, and invasion by downregulating GRP78}

Having found that P4HB downregulates GRP78 in HCC, we speculated that the oncogenic properties of P4HB in HCC cells might be mediated by GRP78. To test this hypothesis, we examined the function of GRP78 in HCC cell EMT, migration, and invasion. GRP78 overexpression in HepG2 cells significantly increased E-cadherin expression and decreased $\mathrm{N}$-cadherin and vimentin expression; and GRP78 silencing showed the opposite effects (Figure 5A). Thus, in contrast to P4HB, GRP78 suppresses EMT of HCC cells. Consistent with these results, GRP78 overexpression significantly inhibited HepG2 cell migration and invasion; and GRP78 silencing showed opposite effects (Figure 5B, 5C). Importantly, the effects of $\mathrm{P} 4 \mathrm{HB}$ overexpression and silencing on HepG2 EMT, migration, and invasion were reversed by
GRP78 overexpression and silencing, respectively (Figure $5 \mathrm{~A}-5 \mathrm{C})$. These findings provided strong evidence that P4HB promotes HepG2 EMT, migration, and invasion by downregulating GRP78.

\section{P4HB silencing inhibits HCC tumorigenesis in vivo}

To find out whether our in vitro data can be extrapolated to in vivo situation, we established a mouse xenograft model of human HCC. BALB/c nude mice were subcutaneously inoculated with HepG2 cells stably expressing P4HB siRNA or control siRNA. The tumors were harvested after 37 days. Compared with the control group, tumors from the P4HB siRNA group displayed significantly reduced size and weight (Figure $6 \mathrm{~A}-6 \mathrm{C}$ ). Thus, $\mathrm{P} 4 \mathrm{HB}$ promotes HCC tumorigenesis in vivo.

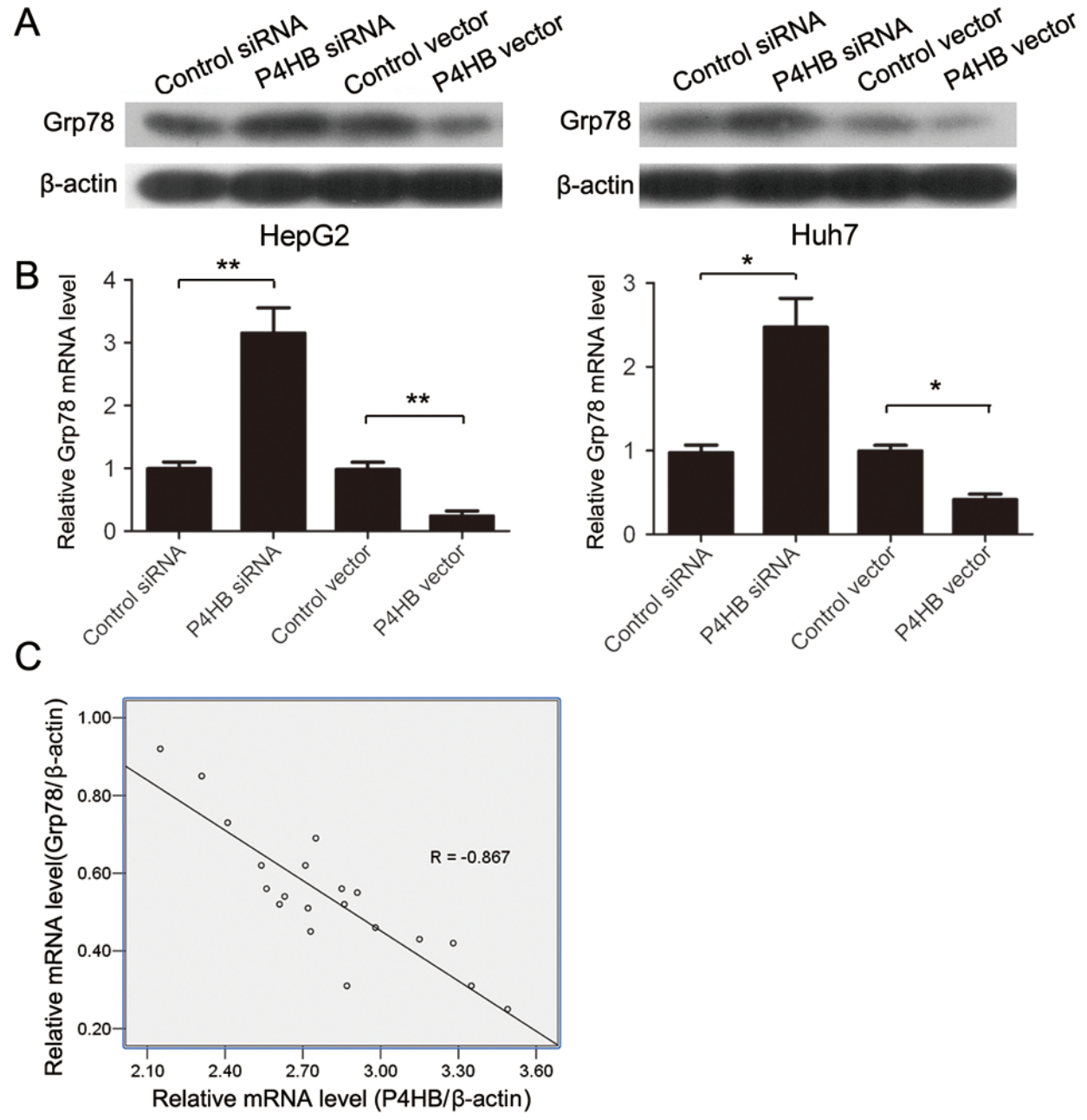

Figure 4: P4HB downregulates GRP78 in human HCC. A, B. HepG2 and Huh-7 cells were transfected with P4HB siRNA, control siRNA, P4HB, or vector alone for $24 \mathrm{~h}$. GRP78 protein and mRNA expression were determined by western blotting (A) and qRTPCR (B), respectively. Data were normalized to $\beta$-actin. $\mathrm{n}=3,{ }^{*} P<0.05,{ }^{*} P<0.01$. C. Correlation analysis of P4HB and GRP78 mRNA levels in human HCC tissues. Data were normalized to $\beta$-actin. $\mathrm{n}=20, \mathrm{R}=-0.867, P<0.001$. 
A
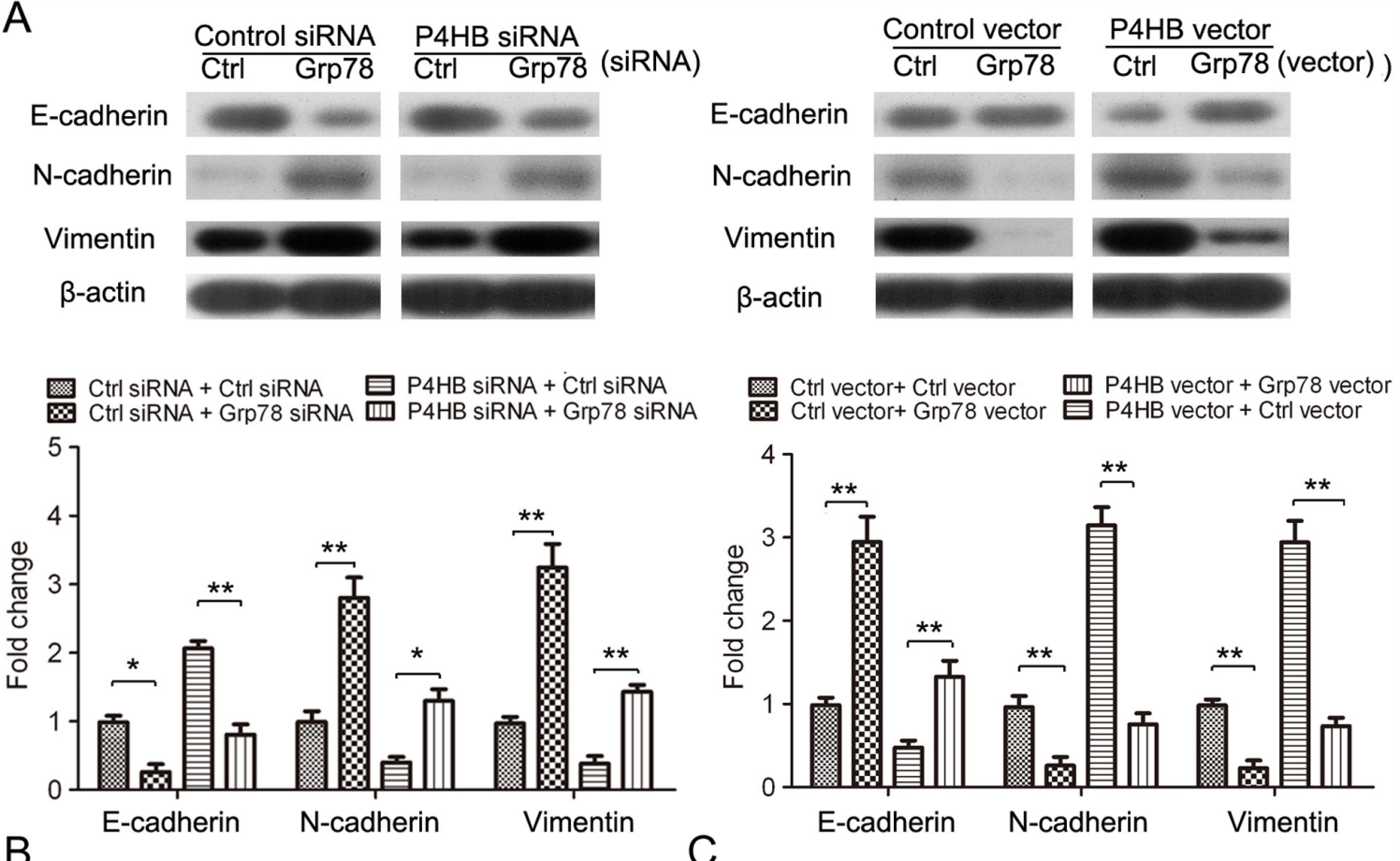

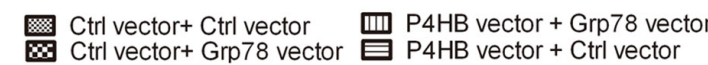
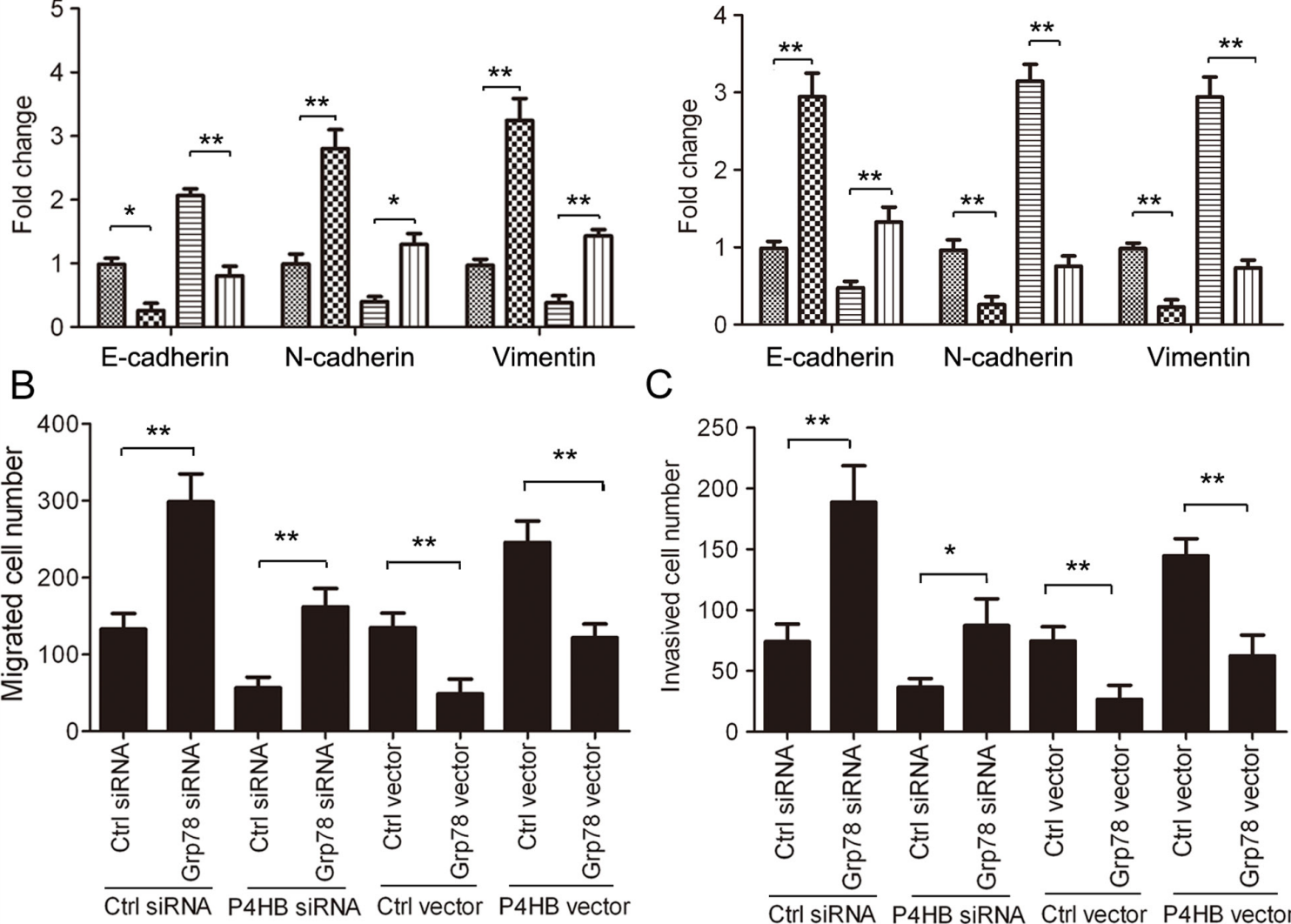

Figure 5: P4HB promotes HCC cell EMT, migration, and invasion by downregulating GRP78. HepG2cells were transfected as indicated for $72 \mathrm{~h}$. A. E-cadherin, $\mathrm{N}$-cadherin, and vimentin protein expression by western blotting. $\beta$-actin was used as a loading control. $\mathbf{B}$ and C. Cell migration (B) and invasion (C) by Transwell assays using un-coated and Matrigel-coated membranes, respectively. $\mathrm{n}=3$, ${ }^{*} P<0.05,{ }^{* *} P<0.01$.
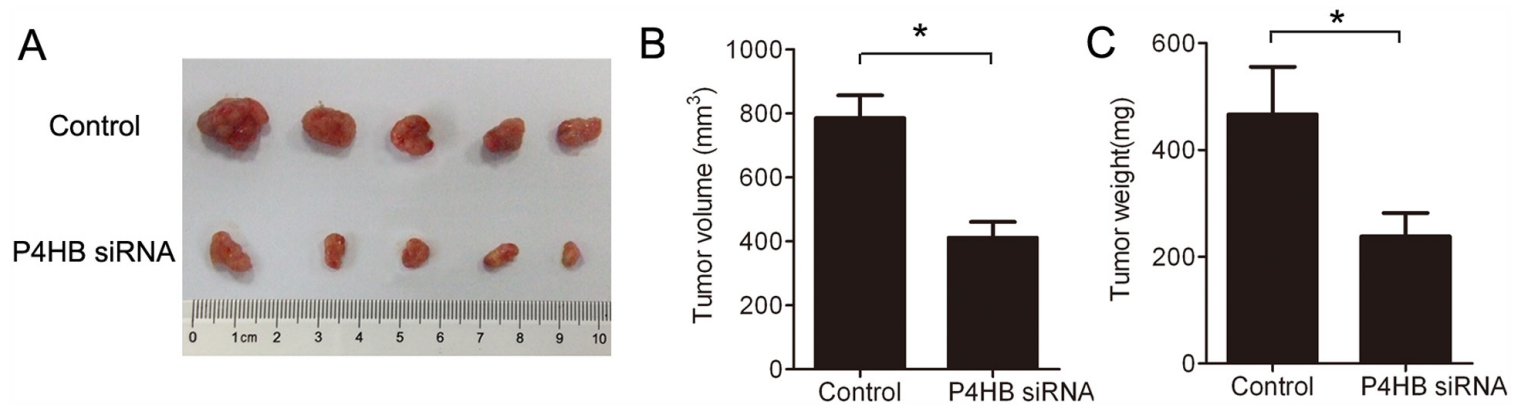

Figure 6: P4HB silencing inhibits HCC tumorigenesis in mice. BALB/c nude mice ( $\mathrm{n}=5$ per group) were subcutaneously inoculated with HepG2 cells stably expressing P4HB siRNA or control siRNA. The tumors were harvested on day 37. A. Tumor image. B. Tumor volume. C. Tumor weights. $* P<0.05$. 


\section{DISCUSSION}

In this study, we found that P4HB is upregulated in human HCC. A higher P4HB expression is correlated with more advance disease and poorer patient survival. To our knowledge, this is the first report on $\mathrm{P} 4 \mathrm{HB}$ as a potential diagnostic/prognostic marker for HCC. One limitation of the current study is the relatively small sample size (42 HCC patients). Univariate and multivariate analyses are warranted in our future studies to evaluate the potential value of P4HB as an independent prognostic factor for overall and diseasefree survival.

In the current study, we also found that P4HB promotes $\mathrm{HCC}$ cell growth, migration, and invasion in vitro and tumor formation in vivo. Intriguingly, $\mathrm{P} 4 \mathrm{HB}$ exerts its oncogenic function in $\mathrm{HCC}$ at least partially by downregulating GRP78, thereby enhancing EMT of HCC cells. P4HB has been linked to cancer cell resistance to the growth-inhibitory effects of transforming growth factor- $\beta 1$ (TGF- $\beta 1$ ) [16]. In addition, P4HB has been reported to protect cancer cells from drug-induced apoptosis; these anti-apoptotic properties of P4HB in cancer cells have been accredited to its function to ameliorate ER stress through interaction with a variety of protein partners [17, 18]. Our findings revealed that P4HB can promote HCC by enhancing EMT through GRP78 downregulation. Whether this applies to other types of cancer waits to be investigated. Suppression of ER stress may also be a contributing mechanism underlying the oncogenic function of P4HB in HCC. Further experiments are required to answer these remaining questions. Findings from this and further studies may be used to harness development of novel therapeutics for HCC treatment.

\section{MATERIALS AND METHODS}

\section{Patients and tissue collection}

The tumor and adjacent normal tissues were collected from 42 HCC patients who underwent surgery at Shanghai Seventh People's Hospital between 2007 and 2011. The study protocol was approved by the Institutional Research Ethics Committee. All study participants gave written informed consent. Clinicopathological parameters of study subjects are shown in Table 1.

\section{Cell lines}

The HCC cell lines Huh-7, HepG2, PLC5, Hep3B, and SK-Hep-1 and the human normal liver cell line L02 were purchased from the Shanghai Institute of Cell Biology, Chinese Academy of Sciences (Shanghai, China). The cells were cultured in Dulbecco's modified Eagle's medium (DMEM; Invitrogen, USA) supplemented with $10 \%$ fetal bovine serum (FBS; Invitrogen), $100 \mathrm{U} /$ $\mathrm{ml}$ penicillin (Invitrogen), and $100 \mu \mathrm{g} / \mathrm{ml}$ streptomycin (Invitrogen) at $37^{\circ} \mathrm{C}, 5 \% \mathrm{CO}_{2}$ in a humidified incubator.

\section{Quantitative reverse transcription real-time PCR}

Total RNA was extracted using the Trizol reagent (Invitrogen) following the manufacturer's instructions. cDNA was synthesized from $1 \mu \mathrm{g}$ RNA using Moloney murine leukemia virus (M-MLV) reverse transcriptase (Invitrogen). The quantitative reverse transcription realtime PCR (qRT-PCR) was carried out using a SYBR Green reaction mix (Applied Biosystems, USA) on an ABI Prism 7900HT sequence detection system (Applied Biosystems). The PCR primer sequences were: P4HB (forward, 5'-GGAATGGAGACACGGCTTC-3'; reverse, 5'-TTCAGCCAGTTCACGATGTC-3') [12], GRP78 (forward, 5'-GCCTGTATTTCTAGACCTGCC-3'; reverse, 5'-TTCATCTTGCCAGCCAGTTG-3'), and $\beta$-actin (forward, 5'-AGCGCGGCTACAGCTTCA-3'; reverse, 5'-GGCCATCTCTTGCTCGAAGT-3') [9].

\section{Western blotting}

Human tissue samples were homogenized in RIPA lysis buffer (Beyotime, China) and stored at $-80^{\circ} \mathrm{C}$ until analysis. The cells were washed with cold PBS and lysed in lysis buffer (Thermo Scientific, USA) containing a complete protease inhibitor cocktail (Boehringer Mannheim, USA). Tissue or cell lysate samples (20 $\mu \mathrm{g}$ total protein) were separated by SDS-PAGE (10\% gel) under reducing conditions and transferred to PVDF membranes (Bio-Rad Laboratories, USA). After blocking in 5\% fat-free milk with $0.05 \%$ Tween 20 in PBS, the membranes were incubated with anti-P4HB, anti-GRP78, anti-E-cadherin, anti-N-cadherin, anti-vimentin, or anti- $\beta$-actin antibody at $4^{\circ} \mathrm{C}$ overnight. After washing, the membranes were incubated with horseradish peroxidase (HRP)-conjugated secondary antibodies (1:5000) at room temperature for $1 \mathrm{~h}$. Protein bands were visualized using an enhanced chemoluminescence reagent (GE Healthcare, USA). The intensity was measured on a VersaDoc 5000 densitometer (BioRad, USA). All primary and secondary antibodies were purchased from Abcam (Cambridge, United Kingdom).

\section{Plasmids, siRNAs, and cell transfection}

Full-length human P4HB and GRP78 cDNAs were generated by PCR and subcloned into the pcDNA3.1 vector. The siRNAs specific for human $\mathrm{P} 4 \mathrm{HB}$ and GRP78 (5'-AAGATGAACTGTAATACGCAA-3' and 5'-AAGGTTACCCATGCAGTTGTT-3', respectively) and a scrambled siRNA used as a negative control were designed and synthesized by GenePharma (Shanghai, China). HepG2 or Huh-7 cells were transfected with the pcDNA3.1 vector, pcDNA3.1-P4HB plasmid, pcDNA3.1-GRP78 plasmid, control siRNA, P4HB siRNA, and GRP78 siRNA, in combination or alone using Lipofectamine 2000 (Invitrogen) for $24 \mathrm{~h}$ and used in in vitro experiments. 


\section{Cell proliferation assay}

Cell proliferation was determined using the MTT assay. HepG2 or Huh-7 cells were transfected with plasmids or siRNAs for $24 \mathrm{~h}$. After the transfection, cells were seeded in 24 -well plates $\left(2 \times 10^{4}\right.$ cells/well $)$ and cultured for up to $72 \mathrm{~h}$. At specific time points, the medium was removed, and the cells were incubated with MTT solution $(0.25 \mathrm{mg} / \mathrm{ml})$ for $1 \mathrm{~h}$. DMSO was added to dissolve the formazan crystals formed, and absorbance at $550 \mathrm{~nm}$ was recorded on a spectrophotometer (GE Healthcare, USA).

\section{Cell migration and matrigel invasion assays}

Cell migration was assessed using a Transwell chamber with $8 \mu \mathrm{m}$ membrane (BD Biosciences, USA). Briefly, $1 \times 10^{5}$ cells were suspended in $500 \mu 1$ of serumfree DMEM and loaded into the upper chamber. The lower chamber was filled with $1 \mathrm{ml}$ growth medium. After $24 \mathrm{~h}$ incubation, the non-migrating cells on the upper surface of the membrane were removed by scraping. The cells that had migrated to the lower surface of the membrane were fixed with $70 \%$ methanol, stained with $0.1 \%$ crystal violet, and counted under an Olympus IX71microscope. To assess cell invasion, cells were serum-starved overnight and loaded to the upper chamber pre-coated with Matrigel $\left(1 \times 10^{5}\right.$ cells/chamber $)$. After $24 \mathrm{~h}$ incubation, the cells that had migrated to the lower surface of the membrane were fixed, stained, and counted as above. Cells in five randomly selected fields of each membrane were counted. Each experiment was conducted in triplicate.

\section{Immunofluorescence analysis}

HepG2 and Huh-7 cells transfected with P4HB siRNA, control siRNA, P4HB, or control vector were grown on 2-well chamber slides (Nalge Nunc International, USA) for $48 \mathrm{~h}$. The cells were subsequently incubated with anti-E-cadherin or anti-vimentin antibody at $4{ }^{\circ} \mathrm{C}$ overnight. After washing with PBS, the cells were incubated with a FITC-conjugated secondary antibody (Vector Laboratories Inc., USA) at room temperature for $1 \mathrm{~h}$. The cells were then stained with 4', 6-diamidino-2phenylindole (DAPI) and examined under a Leica SP2 MP confocal microscope (Leica-Microsystems, Germany).

\section{Generation of stable cell lines}

P4HB siRNA or control siRNA were cloned into a doxycycline-inducible tet-on lentiviral vector (Ambion, USA). Constructed lentiviral vectors were generated in HEK293T cells using Trans-Lenti Packaging Kits (Thermo Fisher Scientific Inc., USA). HepG2 cells were infected with viral supernatants $(\mathrm{MOI}=2)$ and selected with $3 \mu \mathrm{g} / \mathrm{ml}$ puromycin (Sigma-Aldrich, USA). Cells stably expressing P4HB siRNA or control siRNA were used for xenograft establishment in nude mice.

\section{Tumor xenografts in mice}

BALB/c nude mice (4-5 weeks of age, 18-20 g) were purchased from the Center of Experimental Animals at Guangzhou University of Chinese Medicine. The animals were and housed in barrier facility on a $12 / 12-\mathrm{h}$ light/dark cycle. All animal studies were approved by the Ethics Committee of Shanghai Seventh People's Hospital. The mouse xenograft model was established as previously described [19]. In brief, the mice were randomly divided into two groups of five mice each ( $n=5$ per group). Mice in one group were subcutaneously inoculated with HepG2 cells $\left(5 \times 10^{6}\right)$ stably expressing control siRNA, and those in the other group with HepG2 cells $(5 \times$ $10^{6}$ ) stably expressing P4HB siRNA. The tumors were harvested on day 37 . Tumor volume and tumor weight were determined.

\section{Statistical analysis}

All data are presented as the mean $\pm \mathrm{SD}$ (standard deviation). Data were interpreted using SPSS 16.0. Multiple comparisons were performed using one-way analysis of variance (ANOVA). Differences with a $P$ value less than 0.05 were considered to be statistically significant.

\section{ACKNOWLEDGMENTS}

The study was supported by grants from Natural Science Foundation of China (No. 81371597 and 81571718), Shanghai Sailing Program (No.16YF1408800), Shanghai Pudong Science and Technology Committee Foundation (Grant no. PKJ2016-Y50) and Key disciplines Group Constraction Project of Pudong Health Burea of Shanghai(PWZxq2014-12).

\section{CONFLICTS OF INTEREST}

We declare that we have no conflicts of interest.

\section{REFERENCES}

1. Lee AS, Hendershot LM. ER stress and cancer. Cancer Biol Ther. 2006; 5:721-2. doi:

2. Feldman DE, Chauhan V, Koong AC. The unfolded protein response: a novel component of the hypoxic stress response in tumors. Mol Cancer Res. 2005; 3:597-605. doi: 10.1158/1541-7786.MCR-05-0221.

3. $\mathrm{Fu} \mathrm{Y,} \mathrm{Lee} \mathrm{AS.} \mathrm{Glucose} \mathrm{regulated} \mathrm{proteins} \mathrm{in} \mathrm{cancer}$ progression, drug resistance and immunotherapy. Cancer Biol Ther. 2006; 5:741-4. doi: 
4. Fels DR, Koumenis C. The PERK/eIF2alpha/ATF4 module of the UPR in hypoxia resistance and tumor growth. Cancer Biol Ther. 2006; 5:723-8. doi:

5. Zhu G, Lee AS. Role of the unfolded protein response, GRP78 and GRP94 in organ homeostasis. J Cell Physiol. 2015; 230:1413-20. doi: 10.1002/jcp.24923.

6. Lee AS. GRP78 induction in cancer: therapeutic and prognostic implications. Cancer Res. 2007; 67:3496-9. doi: 10.1158/0008-5472.CAN-07-0325.

7. Hardy B, Raiter A, Yakimov M, Vilkin A, Niv Y. Colon cancer cells expressing cell surface GRP78 as a marker for reduced tumorigenicity. Cell Oncol (Dordr). 2012; 35:34554. doi: 10.1007/s13402-012-0094-4.

8. Chang YJ, Chen WY, Huang CY, Liu HH, Wei PL. Glucoseregulated protein 78 (GRP78) regulates colon cancer metastasis through EMT biomarkers and the NRF-2/HO-1 pathway. Tumour Biol. 2015; 36:1859-69. doi: 10.1007/ s13277-014-2788-x.

9. Tai CJ, Chin-Sheng H, Kuo LJ, Wei PL, Lu HH, Chen HA, Liu TZ, Liu JJ, Liu DZ, Ho YS, Wu CH, Chang YJ. Survivin-mediated cancer cell migration through GRP78 and epithelial-mesenchymal transition (EMT) marker expression in Mahlavu cells. Ann Surg Oncol. 2012; 19:336-43. doi: 10.1245/s10434-011-1692-5.

10. Noiva R. Protein disulfide isomerase: the multifunctional redox chaperone of the endoplasmic reticulum. Semin Cell Dev Biol. 1999; 10:481-93. doi: 10.1006/ scdb.1999.0319.

11. Xu S, Sankar S, Neamati N. Protein disulfide isomerase: a promising target for cancer therapy. Drug Discov Today. 2014; 19:222-40. doi: 10.1016/j.drudis.2013.10.017.

12. Sun S, Wong TS, Zhang XQ, Pu JK, Lee NP, Day PJ, Ng GK, Lui WM, Leung GK. Protein alterations associated with temozolomide resistance in subclones of human glioblastoma cell lines. J Neurooncol. 2012; 107:89-100. doi: 10.1007/s11060-011-0729-8.
13. Lin H, Yan J, Wang Z, Hua F, Yu J, Sun W, Li K, Liu H, Yang H, Lv Q, Xue J, Hu ZW. Loss of immunity-supported senescence enhances susceptibility to hepatocellular carcinogenesis and progression in Toll-like receptor 2-deficient mice. Hepatology. 2013; 57:171-82. doi: 10.1002/hep. 25991 .

14. Wang SM, Lin LZ, Zhou DH, Zhou JX, Xiong SQ. Expression of prolyl 4-hydroxylase beta-polypeptide in non-small cell lung cancer treated with Chinese medicines. Chin J Integr Med. 2015; 21:689-96. doi: 10.1007/ s11655-013-1535-2.

15. Franco-Chuaire ML, Magda Carolina SC, Chuaire-Noack L. Epithelial-mesenchymal transition (EMT): principles and clinical impact in cancer therapy. Invest Clin. 2013; 54:186205. doi:

16. Sipes NJ, Miller DA, Bascom CC, Winkler JK, Matrisian LM, Moses HL. Altered regulation of protein disulfide isomerase in cells resistant to the growth-inhibitory effects of transforming growth factor beta 1. Cell Growth Differ. 1990; 1:241-6. doi:

17. Lovat PE, Corazzari M, Armstrong JL, Martin S, Pagliarini V, Hill D, Brown AM, Piacentini M, Birch-Machin MA, Redfern CP. Increasing melanoma cell death using inhibitors of protein disulfide isomerases to abrogate survival responses to endoplasmic reticulum stress. Cancer Res. 2008; 68:5363-9. doi: 10.1158/0008-5472.CAN-08-0035.

18. Yu SJ, Yoon JH, Yang JI, Cho EJ, Kwak MS, Jang ES, Lee JH, Kim YJ, Lee HS, Kim CY. Enhancement of hexokinase II inhibitor-induced apoptosis in hepatocellular carcinoma cells via augmenting ER stress and antiangiogenesis by protein disulfide isomerase inhibition. J Bioenerg Biomembr. 2012; 44:101-15. doi: 10.1007/ s10863-012-9416-5.

19. Gao M, Kong Q, Hua H, Yin Y, Wang J, Luo T, Jiang Y. AMPK-mediated up-regulation of mTORC2 and MCL-1 compromises the anti-cancer effects of aspirin. Oncotarget. 2016; 7:16349-61. doi: 10.18632/oncotarget.7648. 